\title{
An adaptive design method for understanding tolerance in the precision stamping process"
}

\author{
Xun GONG ${ }^{1,2}$, Yi-xiong FENG ${ }^{\dagger 1}, Z_{i}$-wu REN ${ }^{2}$, Jin $\mathrm{CHENG}^{1}$, Jian-rong TAN ${ }^{1}$ \\ $\left({ }^{1}\right.$ The State Key Laboratory of Fluid Power Transmission and Control, Zhejiang University, Hangzhou 310027, China) \\ ( ${ }^{2}$ Robotics and Micro Systems Center, Soochow University, Suzhou 215021, China) \\ †E-mail: fyxtv@zju.edu.cn
}

Received July 23, 2014; Revision accepted Dec. 3, 2014; Crosschecked Apr. 13, 2015

\begin{abstract}
With the development of precision manufacturing, the understanding of tolerance has become a research hotspot in the field of manufacturing. An adaptable design method for understanding tolerance in the precision stamping process is proposed in this study. First, fluctuations of tolerance which are caused by differences in the stamping process are analyzed, such as differences in material and thickness, which can lead to changes in the metal flow stress curve. Second, a condition-driven adaptive design method is constructed based on a monitoring system and hydraulic control system. The mapping rules between multiple disturbance factors and the execution strategy are established by the hidden Markov model algorithm. Third, executive parameters, such as velocity, pressure, and gaps, are calculated and optimized by the data statistics of partial tolerance fluctuations in the control module. Then disturbances of various conditions could be adaptively controlled timely and effectively by the executive parameters. Finally, the adaptive design method for tolerance of one precision stamping part is applied, and the effect of the application is proved by the optimized results.
\end{abstract}

Key words: Adaptive design, Tolerance, Condition-driven, Precision stamping process doi: $10.1631 /$ jzus.A1400220

\section{Introduction}

As society advances, product quality requirements are continuously improved in the marketplace. Manufacturing enterprises are facing increasing cost and technical pressures in the production of precision parts. High quality parts, which with high dimensional accuracy, smooth blanked surfaces, and good

\footnotetext{
${ }^{\ddagger}$ Corresponding author

* Project supported by the National Natural Science Foundation of China (Nos. 51322506, 51175456, and 51305284), the National Basic Research Program (973) of China (No. 2011CB706702), the Zhejiang Provincial Natural Science Foundation of China (No. LR14E050003), the Fundamental Research Funds for the Central Universities, and the Innovation Foundation of the State Key Laboratory of Fluid Power Transmission and Control, Zhejiang University, China

(D) ORCID: Xun GONG, http://orcid.org/0000-0001-9346-9542; Yi-xiong FENG, http://orcid.org/0000-0001-7397-2482

(C) Zhejiang University and Springer-Verlag Berlin Heidelberg 2015
}

interchangeability, can be obtained through precision stamping technology processing. Some subsequent processing operations can be reduced or even cancelled, such as leveling and grinding. Product quality and production efficiency can be improved by precision stamping processes at a relatively low cost. In industrialized countries, precision stamping technology is becoming more widely applied in various industrial sectors including automobile manufacturing (Weng and $\mathrm{Xu}, 2012$ ).

In the actual production environment, production support is highly dependent on precision stamping processes, including fine blanking equipment, tooling, materials, processing environment, operators, and lubrication. For example, the edge length and runout of precision parts can be influenced by material hardening or temperature fluctuations, which could lead to drift tolerance. So further research 
concerning tolerance design in precision stamping processes is urgently needed and it would also help to promote the popularization and application of precision stamping processes.

As technology advances, many researchers have made a lot of achievements in the field of dimensional tolerances design and control. In 1983, an offsetting tolerance zone theory was proposed, which laid the theoretical basis for computer-aided tolerance design (Requicha, 1983). Virtual boundary requirements (VBR) were proposed to restrict the maximum physical condition and the smallest entity state of the parts, and then tolerance specification language was used to describe the VBR model (Etesami, 1993). The computer-aided tolerance optimal design method was proposed by using the simplified integrating region and Monte Carlo simulation (Wu and Yang, 1999). The robust tolerance design method was studied for manufacturing (Cao, 2003). A new functional tolerancing method was presented for a geometrical functional requirement to geometrical specification (Yang et al., 2010). Meanwhile, some other research related to computer-aided tolerance design were being proposed, such as sequential tolerance control (STC) (Fraticelli et al., 1997; 1999), some extension applications of sequential tolerance control (Cavalier and Lehtihet, 2000), a low-cost fault tolerance approach (Vakili et al., 2009), material selection strategy for optimal structural design (Qiu et al., 2013), and a multi-physics coupling field finite element analysis (Zhao et al., 2009).

Tolerance is the amount of variation permitted in the part or the total variation allowed in a given dimension. The required geometry variation range of parts (tolerance) should be provided in the designs for machinery manufacturing. The fluctuation of the part geometry should be controlled in the required variation range to ensure the requirements of interchangeability and assembling. The part geometry would inevitably fluctuate because of disturbance factors in the manufacturing process. The monitoring system and operation modules are constructed on the basis of numerical control technology. The computeraided system is built to control process parameter adaptively. The fluctuation of the part geometry would be ensured in the tolerance range by this method.

In this sutdy, we analyzed the reasons for tolerance fluctuations, constructed the condition-driven adaptive design method for tolerance by using the hidden Markov model algorithm, and then presented the results of some experiments on the precision stamping process and discussed the feasibility and effectiveness of the adaptive design method.

\section{Tolerance fluctuation analyses}

Precision parts are produced based on geometric dimensions and process routes determined during detailed design. Aiming for high quality, operators process the raw material into parts using equipment in the production environment. There are inevitable disturbance factors (such as man, material, machine, method, measure, and environment (5M1E)) in the production environment affecting the processing quality. Tolerance fluctuations are caused by $5 \mathrm{M} 1 \mathrm{E}$ in the manufacturing process which results in a loss of quality. Tolerance fluctuations would cause geometry errors of the precision parts in the manufacturing process, while there will also be dimension and position errors. The form and position errors impact the performance of the parts (assembly, structural strength, contact stiffness, interchangeability, sealing, motion accuracy, and meshing, etc.) in varying degrees. The influence is even more serious in a hostile environment such as high temperature and pressure.

To guarantee the processing quality, form and position errors of the parts geometry elements need to be restricted. Therefore, geometry features of the parts are required to meet geometric tolerances to restrict the form and position errors in the tolerance range. Characteristics of form and position errors include geometric size, the scope of the changes, and the direction and position of the parts. According to the Pareto principle, a few key condition factors cause most of the tolerance fluctuations. In the production process, the variation of geometric parameters is controlled in the tolerance fluctuations range by adjusting the critical condition factors.

Engineered raw materials are generally made from steel because of its excellent characteristics. There would not be any permanent deformation under the load stress which is less than the proof stress. In addition, it can be processed into almost any shape under a large enough load stress.

When the load stress is less than the proof stress, the strain $\varepsilon$ is proportional to the stress $\sigma$. The final 
value of the strain is determined by the modulus of elasticity and obeys Hooke's law:

$$
\varepsilon=\frac{\sigma}{E}
$$

where $E$ is a constant.

When the load stress exceeds the proof stress, metallic materials begin to flow. The required stress can be obtained by the Hall-Petch formula:

$$
R_{\mathrm{e}}=\sigma_{\text {iy }}+\Delta \sigma_{\mathrm{c}}+\Delta \sigma_{\mathrm{v}}+\Delta \sigma_{\mathrm{o}}+k_{\mathrm{y}} / \sqrt{d},
$$

where $R_{\mathrm{e}}$ is the elastic limit, the load stress when the metal begins to flow; $\sigma_{\mathrm{iy}}$ is the Peierls stress, the internal friction which must be overcome when the metal flows; $\Delta \sigma_{\mathrm{c}}$ is the increment of strength of materials caused by the solid solution intensification; $\Delta \sigma_{\mathrm{v}}$ is the increment of strength of the materials caused by strain hardening; $\Delta \sigma_{0}$ is the increment of strength of materials caused by dispersion strengthening; $k_{\mathrm{y}} / \sqrt{d}$ is the increment of strength of the materials caused by fine-grain strengthening; $k_{\mathrm{y}}$, the resistance of the grain boundary, is constant; and $d$ is the diameter of the grain. Eq. (2) shows that the elastic limit of the metal material is the superposition of the values of different mechanisms. These values constitute the material strength.

Phenomena such as Peierls stress, strain hardening, and fine-grain strengthening of the metallic material could appear when the load stress exceeds the proof stress. Fig. 1 is the schematic diagram of the plastic deformation of metallic materials in the precision stamping testing process.

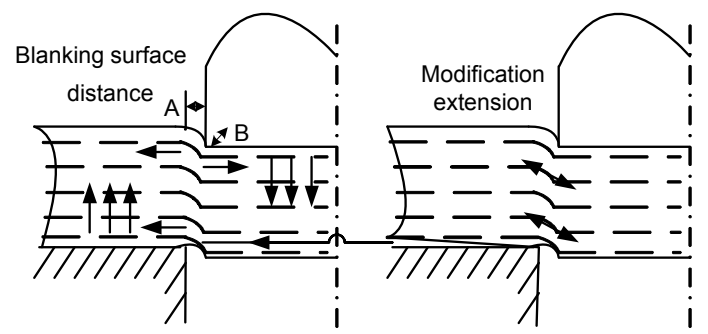

Fig. 1 Plastic deformation of metallic materials

The gain structure of material forming in the zone will change in the metal forming processes, such as stamping, deep drawing, bending, and punching. Grains are elongated or compressed along the direction of the processing, and accompanied by hardening. Strength characteristics, such as yield strength, tensile strength, or hardness, would be enhanced because of the hardening effect. But at the same time, toughness characteristics, such as elongation, constriction, and impact properties, would be reduced. Geometric tolerance of precision parts could fluctuate significantly because of grain flow and intensity changes in the stamping process.

Stamping trials were conducted using two types of steel materials (Q345 and 35\#) to study the hardening state. The measurement data were carried out by quadratic fit. Fig. 2 and Fig. 3 were obtained to show stress variation in the steel.

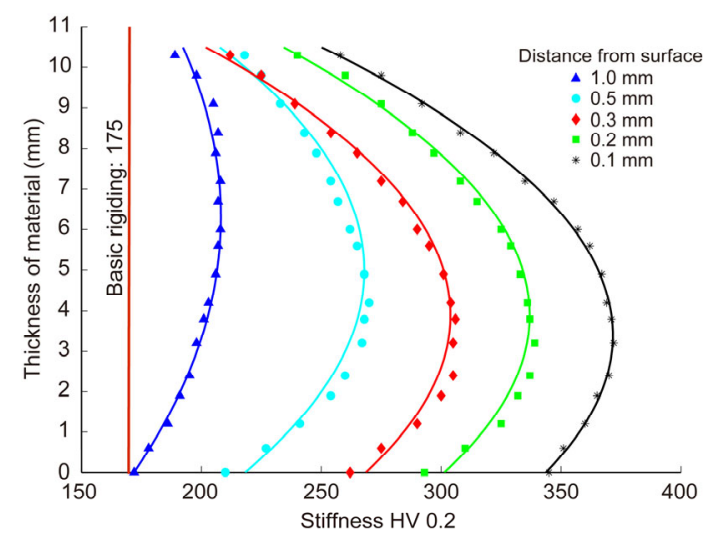

Fig. 2 Hardening state curves of Q345

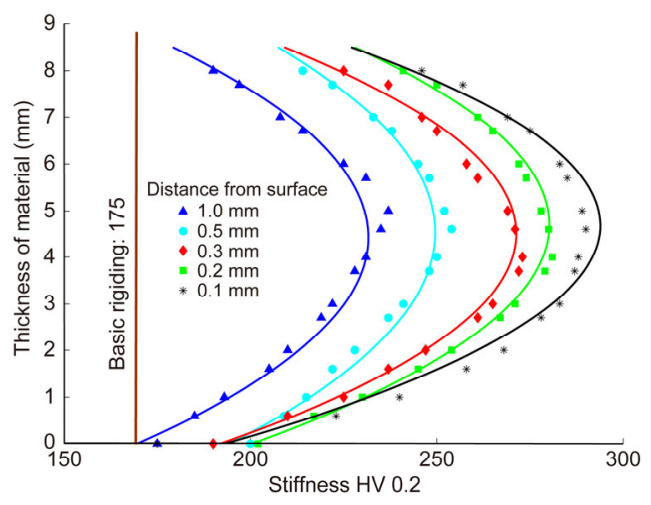

Fig. 3 Hardening state curves of 35\#

The fitting curve of the experimental data is shown in Fig 2. The test object was a generic steel material (No. Q345). The average curvatures of the hardening state curves of the material forming were different with different distances to the precision 
stamping surface when the load stress exceeded the proof stress. The smaller the distance, the greater the material hardening change. The hardening degree of distance $0.1 \mathrm{~mm}$ was greater than $1 \mathrm{~mm}$ (Fig. 2). The same situation happens in Fig. 3 with the test object No. 35\#. The basic strength of the material stayed the same when the load stress was less than the proof stress or the distance was more than $1 \mathrm{~mm}$ (which is shown as the vertical line).

By analyzing the results shown in Figs. 2 and 3, we can see that the hardening state curves of different materials were different. Under the same distance, the values of the hardening state of different materials were different. Stiffness presents the physical parameter of pressure in the stamping process. Oriented to different raw materials, thickness, and molds, fluctuations of geometric tolerance were caused and the processing quality decreased without the adaptive design for the pressure control.

The precision stamping process was constitutive of the stamping equipment, steel, mold, and other condition factors. Process parameters included the stamping speed, pressure, material type, thickness of steel, geometries, structure and precision of the mold, temperature, lubrication, humidity, and so on. The disturbances of these parameters would result in a series of system errors and random errors to lead tolerance fluctuations. The precision stamping process was adaptively controlled based on the change status of these disturbance factors to minimize the volatility of the manufacturing tolerances.

\section{Adaptive design model}

The precision stamping device is constituted by the function, behavior, structure, carriers, and other design elements. In the mechanical system design theory, there are reciprocating mapping relationships among function domain (F-domain), behavior domain (B-domain), and carrier domain (C-domain) (Umeda et al., 1990). Functionality is achieved by the combination of product behavior. Behavior is performed by the carriers. The carrier is the basis of components that make up the complete device. During the precision stamping process, the device performance degrades because of condition fluctuations.

The state data are traced back to the source of the fluctuations in condition factors by the hidden Mar- kov model (HMM). The carrier domain is calculated through the mapping relationships of the device structure. Feedback of the tolerance fluctuations is regulated by controlling the execution parameters of the carrier. Then a closed-loop feedback adaptive control system for computer-aided tolerance can be proposed.

The HMM is a doubly stochastic process on the basis of the Markov chain. One is the Markov chain that describes the transfer of the states. Another describes the corresponding relationships with statistics between the states and the monitoring data. Real random states of the process are hidden in the monitoring data. The observation process is completely determined by the real states of the process. The status of the condition disturbance factors which are monitored by the sensors is random in the precision stamping process. As with the process conditions, machining quality cannot be obtained directly from the monitor. States of tolerance fluctuations of parts are hidden in the monitoring data of the conditional disturbance factors. States and trends of tolerance fluctuations of parts are calculated by the HMM in the adaptive control method of tolerance.

The HMM is expressed by the following five parameters (Rabiner, 1989):

$N$ : The number of hidden states $\left(\theta_{i}\right)$ of the hidden Markov chain is expressed as $N$, and the states are expressed as $S$. The state of the hidden Markov chain at time $t$ is expressed as $q_{t}$.

$$
\begin{aligned}
& S=\left\{\theta_{1}, \theta_{2}, \cdots, \theta_{N}\right\}, \\
& q_{t} \in\left\{\theta_{1}, \theta_{2}, \cdots, \theta_{N}\right\} .
\end{aligned}
$$

$M$ : The number of different values monitored by the corresponding sensors in the process is expressed as $M$. The set of monitoring values is represented as $V$, and $v_{i}$ is the element of the set $V$.

The monitoring value at time $t$ is expressed as $o_{t}$.

$$
o_{t} \in\left\{v_{1}, v_{2}, \cdots, v_{M}\right\} \text {. }
$$

$\pi$ : The probability distribution of the initial state $\left(q_{t}\right)$ in the process is expressed as $\pi$.

$$
\pi=\left\{\pi_{1}, \pi_{2}, \cdots, \pi_{N}\right\} .
$$

Supplementary, $\pi_{i}=P\left(q_{1}=\theta_{i}\right)$ and $1 \leq i \leq N$. 
$\boldsymbol{A}$ : The state transition probability matrix is expressed as $\boldsymbol{A}$.

$$
\begin{gathered}
\boldsymbol{A}=\left(a_{i j}\right)_{N \times N}, \\
\pi_{i}=P\left(q_{1}=\theta_{i}\right) \text { and } 1 \leq i \leq N, 1 \leq j \leq N .
\end{gathered}
$$

$\boldsymbol{B}$ : The monitor value probability matrix is expressed as $\boldsymbol{B}$.

$$
\begin{gathered}
\boldsymbol{B}=\left(b_{j k}\right)_{N \times M}, \\
b_{j k}=P\left(o_{t}=v_{k} \mid q_{t}=\theta_{j}\right) \text { and } 1 \leq j \leq N, 1 \leq k \leq N .
\end{gathered}
$$

The states of tolerance fluctuations are identified by the following three steps:

Step 1: Initial values selection. Statistical data of the tolerance fluctuations in the precision stamping process are analyzed. The initial values of $\boldsymbol{A}$ and $\boldsymbol{B}$ are selected in the historical statistics to meet the constraints of Eqs. (3)-(7).

Step 2: Model training. The probability is defined as $\xi_{t}(i, j)$ when HMM is in state $\theta_{i}$ at time $t$, while in state $\theta_{j}$ at time $t+1$ based on the given training sequence $O$ and model $\lambda$.

$$
\xi_{t}(i, j)=P\left(q_{t}=\theta_{i}, q_{t+1}=\theta_{j} \mid O, \lambda\right) .
$$

The probability of Markov chain in the state $\theta_{i}$ at time $t$ is expressed as $\gamma_{t}(i)$ :

$$
\gamma_{t}(i)=\sum_{j=1}^{N} \xi(i, j)=\frac{\left[a_{t}(i) b_{t}(i)\right]}{P(O \mid \lambda)} .
$$

Parameters are conducted by several iterative operations by using the revaluation formula of the Baum-Welch algorithm. Convergent parameters of the model $\tilde{\lambda}=(\tilde{\pi}, \tilde{\boldsymbol{A}}, \tilde{\boldsymbol{B}})$ were obtained to meet the requirements of the error range.

$$
\begin{gathered}
\bar{\pi}=\gamma_{1}(i), \\
\bar{a}_{i j}=\sum_{t=1}^{T-1} \xi_{t}(i, j) / \sum_{t=1}^{T-1} \gamma_{t}(i), \\
\bar{b}_{j k}=\sum_{\substack{t=1 \\
\text { s.t. } o_{t}=v_{k}}}^{T} \gamma_{t}(j) / \sum_{t=1}^{T} \gamma_{t}(j) .
\end{gathered}
$$

Step 3: State solution. State sequence $\Theta$ is estimated by the Viterbi algorithm in those cases when the value of $P(\Theta \mid V)$ is at the maximum. It can be calculated by the Bayes formula:

$$
P(\Theta \mid V)=\frac{P(\Theta) P(V \mid \Theta)}{P(V)} .
$$

The discriminated function is defined as $g_{\Theta}(V)$ because $P(V)$ has no impact on the estimation method:

$$
g_{\Theta}(V)=P(\Theta) P(V \mid \Theta)
$$

According to a first-order Markov process, the following equations can be expressed:

$$
\begin{aligned}
P(\Theta) & =P\left(\theta_{1}, \theta_{2}, \cdots, \theta_{n}\right) \\
& =P\left(\theta_{1}\right) P\left(\theta_{1} \mid \theta_{2}\right) \cdots P\left(\theta_{n} \mid \theta_{n-1}\right), \\
P(V \mid \Theta) & =P\left(\left(v_{1}, v_{2}, \cdots, v_{n}\right) \mid\left(\theta_{1}, \theta_{2}, \cdots, \theta_{n}\right)\right) \\
& =P\left(v_{1} \mid \theta_{1}\right) P\left(v_{2} \mid \theta_{2}\right) \cdots P\left(v_{n} \mid \theta_{n}\right) .
\end{aligned}
$$

The following formula can be obtained after transformation:

$$
\begin{aligned}
g_{\Theta}(V) & =P(\Theta) P(V \mid \Theta)=P\left(\theta_{1}\right) P(V \mid \Theta) \\
& =\prod_{t=2}^{n} P\left(\theta_{t} \mid \theta_{t-1}\right) \prod_{t=1}^{n} P\left(v_{t} \mid \theta_{t}\right) .
\end{aligned}
$$

Eq. (15) was carried out by the logarithm operation due to the same monotonicity between $\lg x$ and $x$.

$$
\begin{aligned}
\lg g_{\Theta}(V)= & P\left(\theta_{1}\right)+P\left(v_{1} \mid \theta_{1}\right) \\
& +\sum_{t=2}^{n}\left(P\left(\theta_{t} \mid \theta_{t-1}\right)+P\left(v_{t} \mid \theta_{t}\right)\right) .
\end{aligned}
$$

The model parameters of HMM are obtained by revaluating the monitoring data. The maximum values of the sub-state are calculated for each state at each time. The sequence $\Theta$ of the state values at each time can be obtained by accumulating the sub-state values. The sequence is the hidden tolerance fluctuant states in the precision stamping process.

Once the volatility of the tolerance fluctuations exceeded the tolerance range in design, the adaptive control strategy would be activated in the computer numerical control system. The process execution parameters were adjusted adaptively to reduce the volatility. 


\section{Simulation results and discussion}

A precision stamping process is used to cut or mold materials based on the plastic shear theory, and it is pressed on a dedicated piece of press equipment using a precision die with a non-traditional structure. The precision stamping process makes the materials to generate the plastic deviatoric deformation under huge pressure. With the extensive application of new materials and computer technology, the high required accuracy of the geometric dimensions of various components has increased. The adaptive design method is proposed to control the process parameters which would reduce the tolerance fluctuations. It is a very significant approach for improving the processing quality and accuracy in the precision stamping process. Fig. 4 is a design model of a dedicated die in the precision stamping process.

The compound die mainly includes a blanking die, punch-die, drawing punch, and the blank holder ring parts. In the precision stamping process, first, a $\mathrm{V}$-shaped gear ring is placed under the pressure $F_{x}$. The material is pressed into a concave mold. Then the lateral side pressure is formed on the inner surface of the $\mathrm{V}$-shaped gear ring to effectively prevent the

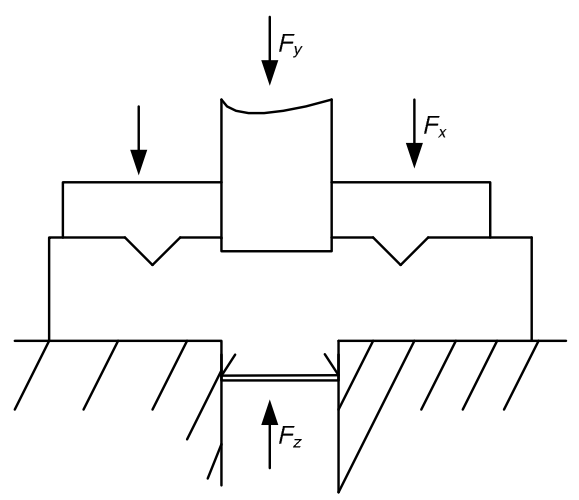

Fig. 4 Design model of dedicated die tearing and lateral flowing of the metallic materials in the shear region. The steel sheet is constricted by the blanking die under the combined pressure effects of the load stress $F_{x}$ and the back pressure $F_{z}$ of the ejector plate. Once the state of the material is completely pressed, the material is stamped by the pressing stress $F_{y}$.

Precision stamping tests were carried out several times under the traditional processing methods on steel materials (No. 35\#). The test data is shown in Table 1.

Basic process parameters were held constant, while some particular condition factors were allowed to fluctuate in the trials. It was shown that the volatility of the tolerance fluctuation was different in different trials. Comparing three sets of data from trials $S_{1}, S_{2}$, and $S_{3}$, the tolerance changes by 0.070 , 0.035 , and 0.024 , respectively. The fluctuation range is about 0.028 . By analyzing the trials $\mathrm{S}_{2}, \mathrm{~S}_{4}$, and $\mathrm{S}_{5}$, the fluctuation range is about 0.270 . The amount of the fluctuation range for this data set is 10 times that of the former. The fluctuation range should be reduced by redesigning the process parameters when the condition factors change.

Process parameters were adjusted adaptively under the adaptive method by the monitoring system and HMM algorithm in five different types of tests. The simulations of the adaptive process parameters are shown in Figs. 5-9. The results of the adaptive control method of tolerance in the precision stamping process are shown in Table 2.

The relationships among the stamping pressure, breakpoints, and the displacement of the punch were obtained by fitting curves in Matlab. The results can be seen in Figs. 5-9. As the blanking clearance increased (as trials $\mathrm{S}_{1}, \mathrm{~S}_{2}$, and $\mathrm{S}_{3}$ ), the displacement of the punch increased non-linearly $(0.235,0.262$, and 0.296), and the maximum stamping pressure decreased $(2.04,2.01$, and 1.96). The fluctuation range

Table 1 Measured data of the experiments in five states

\begin{tabular}{ccccccccccccc}
\hline Trial & $\begin{array}{c}\text { Blanking } \\
\text { clearance } \\
(\mathrm{mm})\end{array}$ & $\begin{array}{c}\text { Radius of Fillet radius } \\
\text { punch } \\
(\mathrm{mm})\end{array}$ & $\begin{array}{c}\text { Radius } \\
\text { of punch } \\
(\mathrm{mm})\end{array}$ & $\begin{array}{c}\text { Fillet } \\
\text { of die } \\
(\mathrm{mm})\end{array}$ & $\begin{array}{c}\text { Thickness } \\
\text { rie }(\mathrm{mm})\end{array}$ & $\begin{array}{c}\text { Velocity } \\
\text { of steel }\end{array}$ & $\begin{array}{c}\text { Metal } \\
(\mathrm{mm} / \mathrm{s})\end{array}$ & $\begin{array}{c}\text { Pressure } \\
\text { type }\end{array}$ & $\begin{array}{c}\text { Dis- } \\
\left(\times 10^{4} \mathrm{~N}\right)\end{array}$ & $\begin{array}{c}\text { Distance of } \\
\text { placement } \\
(\mathrm{mm})\end{array}$ & $\begin{array}{c}\text { Tolerance } \\
\text { fracture } \\
(\mathrm{mm})\end{array}$ & $\begin{array}{c}\text { fluctuation } \\
(\mathrm{mm})\end{array}$ \\
\hline $\mathrm{S}_{1}$ & 0.05 & 9.95 & 0.1 & 10 & 0.1 & 1 & 20 & $35 \#$ & 2 & 0.260 & 0.330 \\
$\mathrm{~S}_{2}$ & 0.1 & 9.9 & 0.1 & 10 & 0.1 & 1 & 20 & $35 \#$ & 2 & 0.292 & 0.327 & 0.035 \\
$\mathrm{~S}_{3}$ & 0.15 & 9.85 & 0.1 & 10 & 0.1 & 1 & 20 & $35 \#$ & 2 & 0.326 & 0.350 & 0.024 \\
$\mathrm{~S}_{4}$ & 0.1 & 9.9 & 0.1 & 10 & 0.1 & 1.5 & 20 & $35 \#$ & 2 & 0.375 & 0.472 \\
$\mathrm{~S}_{5}$ & 0.1 & 9.9 & 0.1 & 10 & 0.1 & 2 & 20 & $35 \#$ & 2 & 0.498 & 0.097 \\
\hline
\end{tabular}


is about 0.009 . As shown, the thickness of the steel changed (as trials $\mathrm{S}_{2}, \mathrm{~S}_{4}$, and $\mathrm{S}_{5}$ ), the distance of the fracture increased $(0.281,0.362$, and 0.434$)$, and the maximum stamping pressure increased $(2.01,2.01$, and 2.93). The fluctuation range is about 0.017 . Compared with the fluctuation range 0.270 , the fluctuation range was significantly reduced (from 0.270 to 0.017 , turned around $1 / 16$ ). The process quality was significantly improved by using the adaptive design method.

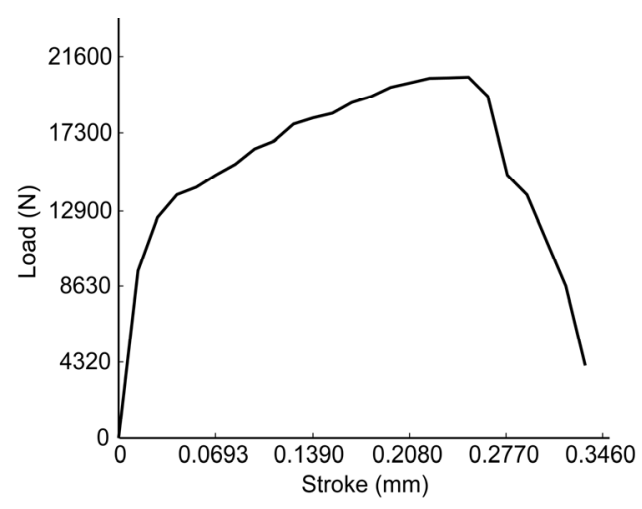

Fig. 5 Simulation of adaptive control in $S_{1}$

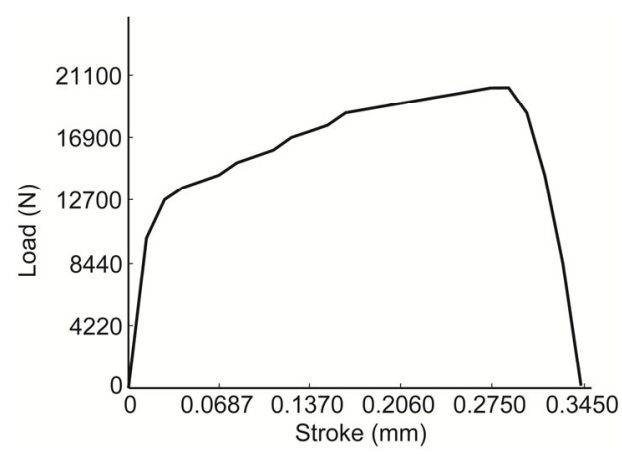

Fig. 6 Simulation of adaptive control in $S_{2}$

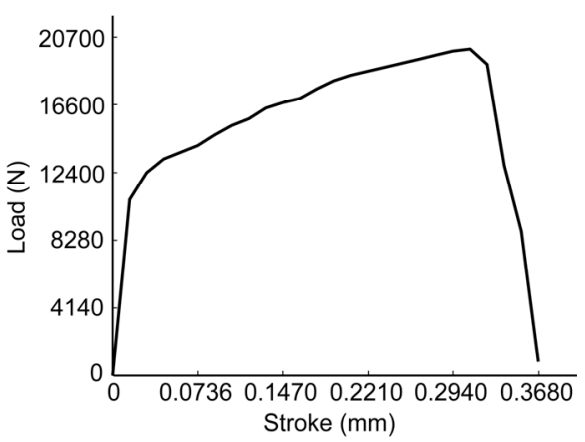

Fig. 7 Simulation of adaptive control in $S_{3}$

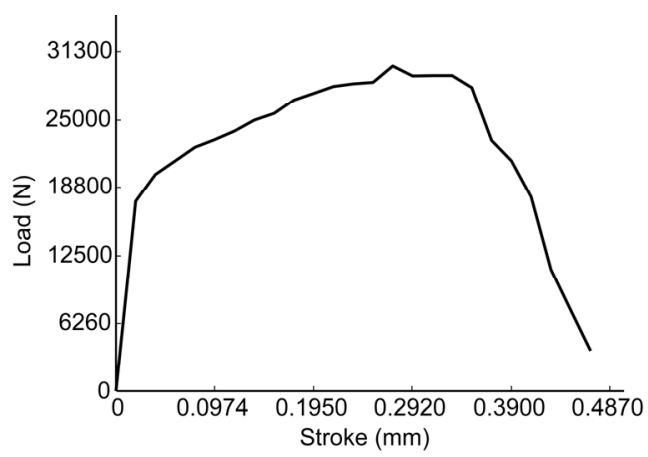

Fig. 8 Simulation of adaptive control in $S_{4}$

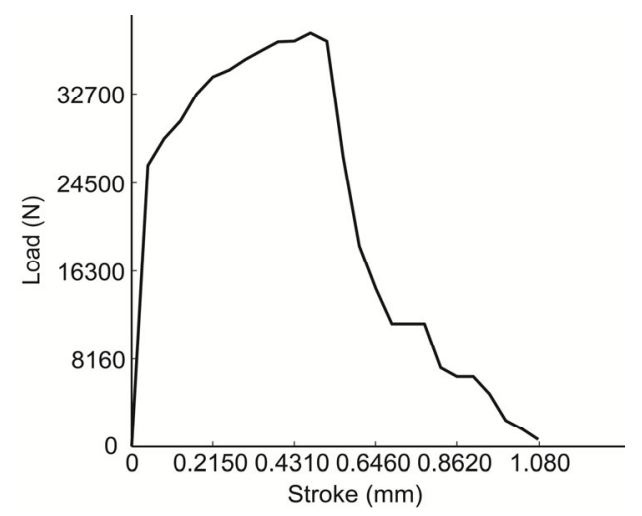

Fig. 9 Simulation of adaptive control in $\mathbf{S}_{5}$

Table 2 Measured data of the experiments in five states

\begin{tabular}{ccccc}
\hline Trial & $\begin{array}{c}\text { Max } \\
\text { pressure } \\
\left(\times 10^{4} \mathrm{~N}\right)\end{array}$ & $\begin{array}{c}\text { Displace- } \\
\text { ment }(\mathrm{mm})\end{array}$ & $\begin{array}{c}\text { Distance } \\
\text { of fracture } \\
(\mathrm{mm})\end{array}$ & $\begin{array}{c}\text { Tolerance } \\
\text { fluctuation } \\
(\mathrm{mm})\end{array}$ \\
\hline $\mathrm{S}_{1}$ & 2.04 & 0.235 & 0.248 & 0.013 \\
$\mathrm{~S}_{2}$ & 2.01 & 0.262 & 0.281 & 0.019 \\
$\mathrm{~S}_{3}$ & 1.96 & 0.296 & 0.318 & 0.022 \\
$\mathrm{~S}_{4}$ & 2.01 & 0.345 & 0.362 & 0.027 \\
$\mathrm{~S}_{5}$ & 2.93 & 0.398 & 0.434 & 0.036 \\
\hline
\end{tabular}

\section{Conclusions}

An adaptive design method to the tolerance fluctuation problem in machining of precision parts has been developed and presented. Status and trends of tolerance fluctuations of parts are calculated by the HMM based on the monitoring data of the press equipment. There are some meaningful observations in this study which are presented as follows:

1. Stamping experiments were conducted in two kinds of steel materials (Q345 and 35\#) to study the 
parameter sensitivity around the distance of the molds or thickness of materials and stiffness.

2. The sequence of the hidden tolerance fluctuant states in the precision stamping process at each time can be obtained by using the HMM algorithm.

3. The adaptive design of the tolerance fluctuations is simulated and analyzed by the precision stamping process through controlling the process parameters, such as pressure of the hydraulic press, displacement of molds, distance of the fracture in materials, and so on.

Several other benefits are foreseen using this method and are actively being investigated. These include: coupling stress of the disturbance factors which fluctuates the tolerance, the generic mechanism which causes the tolerance, the comprehensive program which restricts the form and position errors in the tolerance range.

\section{References}

Cao, Y.L., 2003. Study on the Methodology and Technology of Robust Tolerance Design for Manufacture. PhD Thesis, Zhejiang University, Hangzhou, China (in Chinese).

Cavalier, T., Lehtihet, A., 2000. A comparative evaluation of sequential set point adjustment procedures for tolerance control. International Journal of Production Research, 38(8):1769-1777. [doi:10.1080/002075400188582]

Etesami, F.A., 1993. A mathematical model for geometric tolerances. Journal of Mechanical Design, 115(1):81-86. [doi:10.1115/1.2919329]

Fraticelli, B.P., Lehtihet, E.A., Cavalier, M., 1997. Sequential tolerance control in discrete parts manufacturing. International Journal of Production Research, 35(5):13051319. [doi:10.1080/002075497195335]

Fraticelli, B.P., Lehtihet, E.A., Cavalier, M., 1999. Tool-wear effect compensation under sequential tolerance control. International Journal of Production Research, 37(3): 639-651. [doi:10.1080/002075499191715]

Qiu, L.M., Sun, L.F., Liu, X.J., et al., 2013. Material selection combined with optimal structural design for mechanical parts. Journal of Zhejiang University-SCIENCE A (Applied Physics \& Engineering), 14(6):383-392. [doi:10. 1631/jzus.A1300004]

Rabiner, R.L., 1989. A tutorial on hidden Markov models and selected applications in speech recognition. Proceedings of the IEEE, 77(2):257-286. [doi:10.1109/5.18626]

Requicha, A.G., 1983. Toward a theory of geometric tolerancing. The International Journal of Robotics Research, 2(4):45-60. [doi:10.1177/027836498300200403]

Umeda, Y., Takeda, H., Tomiyama, T., et al., 1990. Function behavior and structure. Applications of Artificial Intelligence in Engineering $V$, 1:177-193.
Vakili, S., Fakhraie, S.M., Mohammadi, S., et al., 2009. Low-cost fault tolerance in evolvable multiprocessor systems: a graceful degradation approach. Journal of Zhejiang University-SCIENCE A, 10(6):922-926. [doi:10. 1631/jzus.A0820803]

Weng, Q.J., Xu, X.C., 2012. Stamping Process and Die Design. China Machine Press, Beijing, China, p.2-12 (in Chinese).

Wu, Z.T., Yang, J.X., 1999. Computer Aided Tolerance Optimization Design. Zhejiang University Press, Hangzhou, China, p.85-124 (in Chinese).

Yang, J.X., Xu, X.S., Cao, Y.L., 2010. Functional tolerance specification design based on assembly positioning. Journal of Mechanical Engineering, 46(2):1-8. [doi:10. 3901/JME.2010.02.001]

Zhao, Z.R., Wu, Y.J., Gu, X.J., et al., 2009. Multi-physics coupling field finite element analysis on giant magnetostrictive materials smart component. Journal of Zhejiang University-SCIENCE A, 10(5):653-660. [doi:10.1631/ jzus.A0820492]

\section{中文概要}

题 目: 面向认知公差的精密冲压工艺适应性设计方法

目 的: 精密冲压工艺过程中环境变量的波动导致工件出 现破裂和皱祽等缺陷。探讨精密冲压工艺过程中 环境变量 (工件材质、冲压速度、压力、模具间 隙和温度变化等) 对冲压质量的影响, 研究适应 性工艺设计方法, 提高精密冲压工件的质量。

创新点: 1 . 通过马尔科夫模型方程, 推导出环境变量与精 密加工波动公差之间的关系; 2 . 建立试验模型, 成功模拟适应性冲压工艺过程。

方 法: 1. 通过实验分析, 推导出冲压过程中的晶粒流动 和强度变化对成型零件的尺寸公差波动产生较 大的影响 (图 2 和 3); 2. 通过理论推导, 构建环 境变量与加工波动公差之间的关系, 得到适应性 的工艺参数调节方案 (公式 16); 3. 通过仿真模 拟, 运用适应性设计方法在精密冲压过程中对工 艺参数进行适应性调节, 验证所提方法的可行性 和有效性（图 5)。

结 论: 1. 精密冲压过程中工艺参数需要根据不同的环境 变量进行调节; 2. 环境变量与加工波动公差之间 存在映射关系, 运用隐马尔科夫模型实现关联表 征; 3. 运用适应性设计方法对精密冲压工艺参数 进行调节, 加工波动公差明显减小, 工件质量得 到提高。

关键词: 适应性设计; 公差; 工况驱动; 精密冲压工艺 